\title{
From the Founding Editor, Dr. Spyros G. Tzafestas
}

\section{$30^{\text {th }}$ Year Anniversary of JINT}

\author{
Spyros G. Tzafestas ${ }^{1}$
}

Published online: 2 June 2018

(C) Springer Science+Business Media B.V., part of Springer Nature 2018

I am really very pleased to write this editorial for the $30^{\text {th }}$ Year Anniversary Special Issue of the Journal of Intelligent and Robotic Systems (JINT). The Journal was founded and launched in 1988 with the aim to provide a forum for exchange of ideas, concepts, and techniques merging systems, control, and robotics science and engineering with AI and other related Computer Science concepts such as intelligent agent theory, distributed intelligence, computational intelligence, etc. Specifically, the motivation for founding the Journal was to provide a common forum for all fields where 'system intelligence' plays a central role, and to stimulate fruitful interaction among researchers and practitioners in the field of intelligent and robotic systems (mechatronic systems, manufacturing systems, automation systems, bioengineering systems, knowledge-based systems, etc.).

I acted as editor of JINT up to August 2006, passing this task to the present Editor-in-Chief, Prof. Kimon Valavanis, an enthusiastic educator and eminent researcher in the field with an extraordinary contribution to the control and robotics societies. He gave immediately a new shape to the journal including a section dedicated to Unmanned Systems with special issues on this subject, and a classification of the submitted papers as Regular, Technical Correspondence, Survey Papers, Invited Papers, and Special Issue Papers. At that time the submission of papers started to be done through the Editorial Manager, an advanced manuscript handling

Spyros G. Tzafestas

tzafesta@cs.ntua.gr

1 Emeritus Professor National Technical University of Athens, Athens, Greece and processing software tool that assists the Editor-in-Chief and the Editors in their work. One of the Journal's best current features is that the Editor-in-Chief and the Editors are able to check for 'duplicate' or 'similar' papers making sure that all papers included in JINT are truly original.

The Journal has received over the years increasing numbers of high quality submissions and it enjoys a continuously increasing impact factor. I would like to congratulate Kimon for his excellent, dedicated and efficient editorial work which, supported by the efforts of the Editorial Board (renewed and enhanced regularly) and Springer's Editorial Team coordinated by Ms. Nathalie Jacobs, has established JINT as one of the major journals in the field.

I feel obliged to mention here the first few names of intelligent systems and robotics workers that have strongly supported the idea of creating JINT, and organized special issues or submitted papers during the initial steps of the journal; it is unfortunate that some of them are not with us any more... Regardless, their names are: G. N. Saridis (RPI), A. Meystel (Drexel), T. Fukuda (Nagoya Univ), M. Jamshidi (UT San Antonio), F. Lewis (UT Arlington), P. Coiffet (Univ. Paris 6), P. Borne (EC Lille), G. Schmidt (TU Munich), H. E. Stephanou (UT Arlington), P. D. Roberts (City Univ., London), U. Rembold (Karlsrue Univ.), G. J. Vachtsevanos (Georgia Tech.), P. Kopacec (TU Vienna), R. Lumia (NIST), I. Troch (TU Vienna), B. P. Zeigler (Arizona Univ.), H. Sunahara (Kyoto Inst. Tech.), R. Tomovic (Belgrade Univ.), and M. Vukobratovic (Mihailo Pupin Inst., Belgrade).

I wish to JINT a long life receiving in the future a stronger acceptance by the scientific community, and publishing even more papers of the highest quality and originality.

Publisher's Note Springer Nature remains neutral with regard to jurisdictional claims in published maps and institutional affiliations. 
Spyros G. Tzafestas was born in Corfu, Greece on December 3, 1939. He earned a B.Sc. in Physics (1962) and a Postgraduate Diploma in Electronics and Communications (1963) from Athens University, D.I.C in Electrical Engineering-Automatic Control Systems from Imperial College of London, M.Sc. (Eng.) in Control from London University in 1967, and Ph.D. in Systems and Control from Southampton University of the United Kingdom in March 1969. He worked at 'Demokritos' Nuclear Research Center as a research leader of the Computer Control and Automation Group of the Computer Science Division from April 1969 to September 1973. From October 1973 to March 1985 he served as a Professor of Control Systems, Director of the Automatic Control Systems Laboratory, at the Electrical Engineering Department of the University of Patras, Patras, Greece. He then gained a position at the School of Electrical and Computer Engineering of the National Technical University of Athens (NTUA) where he served as Professor of Control and Robotics. He founded the Intelligent Robotics and Automation Laboratory of which was the Director up to his retirement on August 31, 2006. From 1999 to 2009 he was the Director of the NTUA Institute of Communication and Computer Systems (ICCS). He holds a D.Sc. (Southampton University, 1978) and two honorary doctorates in engineering (Dr.-Ing. Eh., TU Munich, Germany, 1997, and Docteur ( Honoris Causa), EC Lille France, 2003).

Over the years he worked in the following areas: 1. Distributed parameter control systems, 2. Computing and micro-processor systems, 3. Multivariable and multidimensional systems, 4. Walsh seriesbased modeling and control, 5. Robotic systems, 6. AI, KB, and computational intelligence control techniques, 7. Applications to nuclear reactors and manufacturing systems, and 8. Roboethics/ robophilosophy. He is known for important contributions in the above areas. He is a LIFE FELLOW of IEEE and a FELLOW of IET (IEE). He served as the founding editor of the Journal of Intelligent and Robotic Systems (1988-2006), and he is the Chief Editor of the Springer book series on Intelligent Systems, Control and Automation. $\mathrm{He}$ has edited 30 research books, 20 Conference Proceedings, and 26 journal special issues in his fields of expertise. He has organized and/or chaired many international conferences (IEEE CDC, EUCA, IMACS, IASTED, etc.). He has served as President of EUCA and Vice President of IMACS, and has been the scientific coordinator of many national and European projects in IT, CIM, Robotics, Intelligent Systems, and Control. He is the author of seven international books and seven Greek books on automation, control, robotics and Artificial/Computational Intelligence. He has received many worldwide scientific awards and his biography is included in more than 20 international biographical volumes. Currently, Dr. Tzafestas continues his scientific work at NTUA as a Professor Emeritus-Senior Research Associate of the School of Electrical and Computer Engineering. 